\title{
A COMPARISON OF MICROBIAL FLORA IN PERI-IMPLANT SULCULAR FLUID OF BALL VERSUS LOCATOR RETAINED MANDIBULAR IMPLANT OVERDENTURES. A RANDOMIZED CROSSOVER STUDY
}

\author{
Reham B. Osman* and Ahmed Fahmy**
}

\begin{abstract}
Purpose: To evaluate the microbial flora in peri-implant sulcular fluid of edentulous patients rehabilitated with ball and socket and locator retained mandibular 2-implant overdentures.

Materials and Methods: 14 edentulous patients were recruited to receive two mandibular implant overdentures and new conventional maxillary complete dentures. Mandibular implant overdentures (MIODs) were retained either by locator or ball attachment systems in random order. After 6 months of function, the attachment systems in the existing dentures were replaced with the other type of attachment. The prevalence of streptococci and staphylococci species (spp.) was analyzedusing blood-agar media at 3,6 and 9 weeks after pick-up of attachments. The data was then collected, tabulated and statistically analyzed using SPSS.
\end{abstract}

Results: No significant difference was found in bacterial count of either Streptococcus or Staphylococcus spp. between two attachment systems (Ball and socket, Locator) at any of the evaluated time intervals with $P$-value $>0.05$

Conclusions: Within the limitations of this study, it can be concluded that there is no difference in microbial flora between the two attachment systems. It can also be suggested that the locator attachments are valid treatment alternative for ball abutments to retain mandibular 2-implant overdentures from a biological point of view.

\section{INTRODUCTION}

Mandibular implant overdentures (MIODS) have been successfully used for the rehabilitation of completelyedentulous patients. ${ }^{1,2}$ Various attachment systems have been used to retain IODs. Unsplinted ball and locator attachments are frequently used because of their simplicity and satisfactory clinical and prosthodontic outcomes as well as the improved patients' satisfaction reported with both systems. ${ }^{3,4}$ Different studies have evaluated retentive force, prosthodontic complications, clinical outcomes

* Lecturer, Faculty of Dentistry, Cairo University, Department of Prosthodontics

** Assistant Professor, Faculty of Dentistry, Cairo University, Department of Prosthodontics 
and the financial aspects of these attachments. ${ }^{5,6,7,8,9}$ However, the studies that analyze the peri-implant/ abutment microbiological environment and its influence on the clinical outcome with regards to different overdenture attachments are scarce. ${ }^{10}$

Since overdentures are most commonly employed for elderly and geriatric patients, the oral hygiene tends to worsen with time with subsequent plaque accumulation that occur some time after the dentures delivery. ${ }^{11}$ Plaque accumulating on the exposed surfaces of the biomaterial at the connection between the implant and the abutment or on the abutment surface may alter the microbiota of the oral cavity and result in soft tissue complications such as peri-implant mucositis, hyperplastic mucositis, and some fistulas originating from the soft tissue compartment. ${ }^{12-14}$ The different overdenture attachment designs can also be a contributing factor that influence oral biofilm formation starting with initial bacterial colonization, plaque formation till complete maturation and consequently alter the resultant clinical picture. ${ }^{12,14}$

The locator abutment is designed to have a double aligning, self-retention areas (undercuts) on inner and outer abutment surface. With this pivoting self-aligning design of the locator attachments, there is increased number of undercuts (recesses) that can act as shelter areas for initial colonizer species, such as Streptococcus and Staphyococcus, in locator abutment (patrix) compared to that of the ball attachment. Furthermore, food residues can accumulate in the central depression of the locator patrix that can further complicate the oral hygiene procedures. ${ }^{15}$ Whether, this difference in design of the abutment between the two attachment systems has an influence on the microbial flora on periimplant sulcular fluid has not yet been investigated.

Therefore the aim of this study was to evaluate the prevalence of early colonizers Streptococcus and Staphylococcus species (spp.) in peri-implant sulcular fluid of edentulous patients rehabilitated with ball and locator retained implant overdentures in a crossover study.

\section{MATERIALS AND METHODS}

\section{Study Design}

\section{Patient population \& surgical procedures}

Fourteen edentulous patients from Removable Prosthodontic Department, Faculty of Dentistry, Cairo University participated in this randomized crossover trial. All of those patients experienced functional problems with their conventional mandibular dentures and had sufficient interforaminal bone height and width to receive two implants. The implants (SuperLine, Dentium implant system) were placed following a standardized surgical protocol (Fig 1). Participants with a history of radiotherapy in the head and neck region, heavy smoking of more than 10 cigarettes/day or patients with any systematic condition that can preclude surgical implant procedures were excluded from study. All the participants were informed about the treatment options and an informed consent was obtained.

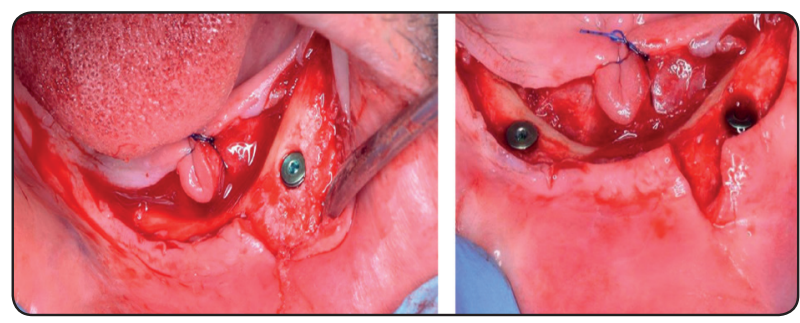

Fig. (1) Implants placement following standard surgical procedures

\section{Prosthodontic procedures:}

Following the inclusion in the study, all the participants received new well-fitted maxillary and mandibular complete dentures according to standard prosthodontic procedures ${ }^{16}$ using balanced occlusal scheme. The dentures were used for 3 months to ensure full adaptation to the newly constructed prostheses. 
Three months following the first stage surgery, the healing abutments were removed and impression copings were installed at implant level. A master cast was then poured and used for the relining of the diagnostic dentures. An experienced laboratory technician performed all laboratory procedures. The patients were randomly selected to initially receive either ball or locator attachment system (Implantium, Implantium II, Superline) and the attachments were changed after 6 months of function. The attachment system was picked up chair side in the fitting surface of the relined denture. Then a wash out period of 1 month was allowed where patients wore the dentures with no attachments in the fitting surface. Following wash out period the other type of attachment system was picked and the patients wore it for further six months so that all the patients received both the locator and ball attachments in an alternating sequence. In such a way, the same denture base was used throughout the whole trial to ensure the reliability of the results. At the end of the trial, patients' wishes regarding their preferred attachment system was fulfilled.

Locator attachment system consisted of double aligning self-retention abutment with retention areas (undercuts) on inner and outer abutment surface and white nylon inserts in the fitting surface of the denture. The ball attachments comprised the conventional ball abutment, female metal housing and plastic O-ring.

\section{Outcome Measures}

\section{Microbiologic Analysis:}

For microbiological sampling, one implant per patient was selected, and the samples were taken on 3 separate occasions from all the subjects at 3, 6 and 9 weeks after the pick-up of attachments. A requisite for site selection was healthy peri-implant sulcus with a sulcus depth of less than $3 \mathrm{~mm}$. The samples were collected at noon (around $12 \mathrm{pm}$ ) giving chance for the patients to use the dentures several hours before taking the swabs. No history of antibiotic administration or use of bacterial disinfectants was recorded within two months before taking the microbiological specimens and patients were instructed not to eat any food before taking the swabs.

The samples were taken by careful air-drying and isolating the gingiva around the implants from moisture contamination with a saliva ejector and cotton pellets placed in buccal and lingual vestibule. Sulcular samples were then taken using a sterile endodontic paper points (Densply Dental,Tianjin) inserted into the peri-implant sulcus on buccal, lingual, mesial and distal for 10 seconds (Fig. 2).

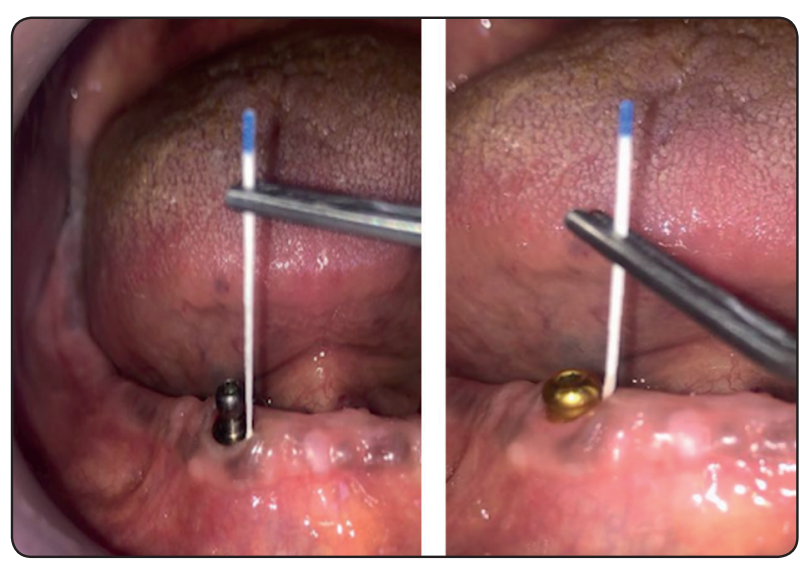

Fig. (2): Microbiological Sampling around ball and socket, and locator attachment

Each sample was then immediately placed in a sterile tube containing $1 \mathrm{ml}$ sterile saline. For each sample, three sterile dilutions of $10^{-1}, 10^{-2}$, and $10^{-3}$ were used. Then 50 micron liter from each dilution were plated onto blood agar plate using a micro pipette, and the samples was then spread on each dilution using a sterile glass rod and incubated thereafter at $37^{\circ} \mathrm{C}$ for 24 hours.

For the quantitative assessment, the visible colonies of each organism were counted in every plate, and the number of colonies/plate was multiplied by the corresponding dilution factor and by 10 to determine the total colony forming units per $\mathrm{ml}$ of suspension (Fig. 3). 


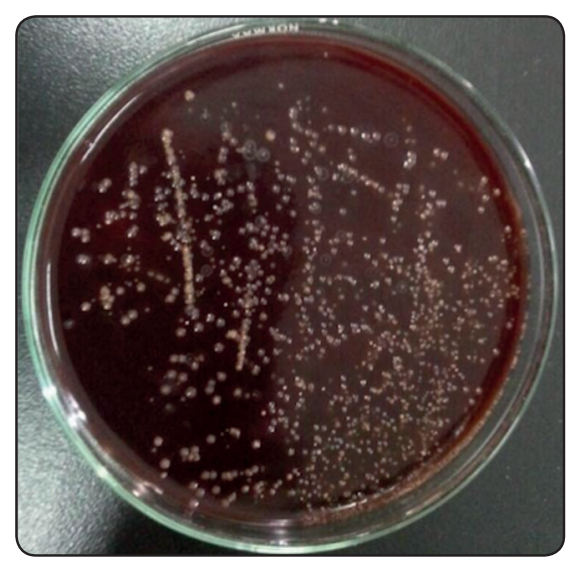

Fig. (3): Bacterial culture on blood agar

\section{Statistical Analysis}

The mean and standard deviation values were calculated for each group. Viable counts of antibacterial activity were transformed to their $\log 10$ values. Data were explored for normality using Kolmogorov-Smirnov and Shapiro-Will tests and showed non-parametric normal distribution.

Independent sample t-test was used to compare between two groups in non-related samples. Repeated measure ANOVA was used compare between more than two groups in related samples. Paired sample t-test was used to compare between two groups in related samples.
The significance level was set at $P \leq 0.05$. Statistical analysis was performed with IBM ${ }^{\circledR}$ SPSS ${ }^{\circledR}$ Statistics Version 20 for Windows.

\section{RESULTS}

No significant difference was found in bacterial count of either Streptococcus or Sstaphylococcus spp. between the two attachment systems or at any of the time intervals (Fig. 4).

\section{Streptococcus Spp.}

No significant difference was found in bacterial count of Streptococcus Spp. between either of the two attachment systems (Table 1).

\section{At 3 weeks interval:}

No statistically significant difference was found between Ball and Socket and Locator attachments $(P=0.353)$.

The highest mean count was found in Locator while the lowest mean count was found in Ball and Socket.

\section{At 6 weeks interval:}

No statistically significant difference was found between Ball and Socket and Locator $(P=0.580)$.

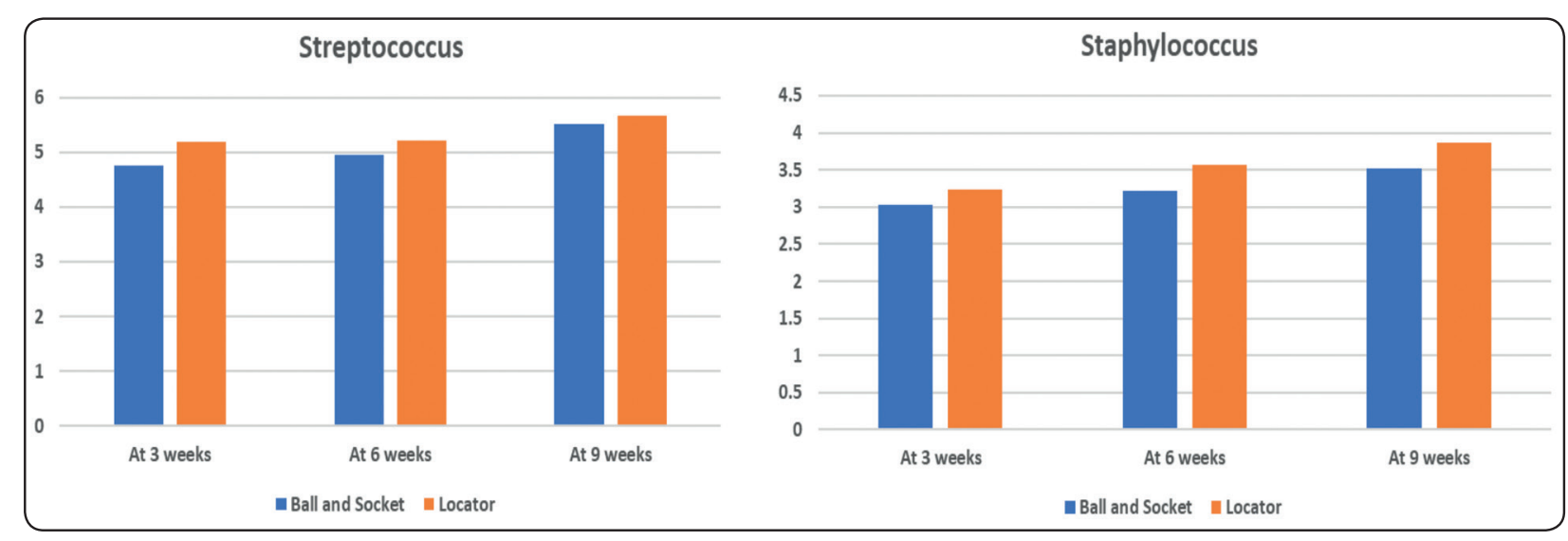

Fig. (4): Bar chart representing Streptococcus \& Staphylococcus count for two different attachments at different time intervals 
The highest mean count was found in Locator group while the lowest mean count was found in Ball and Socket attachment.

\section{At 9 weeks interval:}

No statistically significant difference was found between Ball and Socket and Locator $(P=0.413)$.

The highest mean count was found in Locator while the lowest mean count was found in Ball and Socket.

For both attachment types, no significant difference was found between 3 weeks, 6 weeks and 9 weeks with $P$ Values $=0.26$ and 0.51 respectively for Ball and socket and Locator attachments.
Data in table (2) shows the results of two-way ANOVA analysis for the interaction of different variables. The results showed that different attachments had no statistically significant effect at $P$-value of 0.248 . Also, time period had no significant effect at $P$-value 0.105 . The interaction between the two variables also had no statistically significant effect at $P$-value 0.886 .

\section{Staphylococcus Spp.}

\section{At 3 weeks interval:}

No significant difference was found between Ball and Socket and Locator attachments with $P$ value $=0.481$. The highest mean count was found in Locator group while the lowest mean count was found in Ball and Socket group (Table 3).

TABLE (1) The mean, \& standard deviation (SD) of Streptococcus spp for each attachment at different time interval

\begin{tabular}{|c|c|c|c|c|c|c|c|}
\hline \multirow{3}{*}{ Attachment } & \multicolumn{7}{|c|}{ Streptococcus } \\
\hline & \multicolumn{2}{|c|}{3 weeks } & \multicolumn{2}{|c|}{6 weeks } & \multicolumn{2}{|c|}{9 weeks } & \multirow{2}{*}{ P-value } \\
\hline & Mean & SD & Mean & $\mathrm{SD}$ & Mean & SD & \\
\hline Ball and Socket & 4.75 & 0.67 & 4.94 & 0.81 & 5.52 & 0.53 & 0.263 (ns) \\
\hline Locator & 5.19 & 0.39 & 5.21 & 0.83 & 5.67 & 0.68 & $0.511(\mathrm{~ns})$ \\
\hline P-value & \multicolumn{2}{|c|}{$0.353(\mathrm{~ns})$} & \multicolumn{2}{|c|}{$0.580(\mathrm{~ns})$} & \multicolumn{2}{|c|}{$0.413(\mathrm{~ns})$} & \\
\hline
\end{tabular}

*Significant $P<0.05$, ns; non-significant P>0.05

TABLE (2): Results of Two-way ANOVA for the effect of different variables on Streptococcus count.

\begin{tabular}{|c|c|c|c|c|c|}
\hline Source & Type III Sum of Squares & $\boldsymbol{d f}$ & Mean Square & $\boldsymbol{F}$ & Sig. \\
\hline Corrected Model & $2.959^{\mathrm{a}}$ & 5 & .592 & 1.320 & .289 \\
\hline Intercept & 815.574 & 1 & 815.574 & 1818.948 & .000 \\
\hline Attachment type & .628 & 1 & .628 & 1.400 & .248 \\
\hline Time period & 2.222 & 2 & 1.111 & 2.478 & .105 \\
\hline Attachment type * Time period & .109 & 2 & .055 & .122 & .886 \\
\hline Error & 10.761 & 24 & .448 & & \\
\hline Total & 829.294 & 30 & & & \\
\hline
\end{tabular}

df: degrees of freedom $=(n-1), *$ Significant at $P \leq 0.05$ 


\section{At 6 weeks interval:}

No significant difference was found between Ball and Socket and Locator $(P=0.374)$.

The highest mean count was found in Locator while the lowest mean count was found in Ball and Socket.

\section{At 9 weeks interval:}

No significant difference was found between Ball and Socket and Locator $(P=0.472)$.

The highest mean count was found in Locator while the lowest mean count was found in Ball and Socket.
Similarly, like in Streptococcus spp.no significant difference was found between 3 weeks, 6 weeks and 9 weeks with $P$ Values $=0.23$ and 0.183 respectively for Ball and socket and Locator attachments.

Data in table (4) shows the results of two-way ANOVA analysis for the interaction of different variables. The results showed that different attachments had no significant effect at $P$-value of 0.113 . Also, time period had no statistically significant effect at $P$-value of 0.062 . The interaction between the two variables also had no statistically significant effect at $P$-value of 0.933 .

TABLE (3): The mean, standard deviation (SD) of Staphylococcus spp. for each attachment at different time interval

\begin{tabular}{|c|c|c|c|c|c|c|c|}
\hline \multirow{3}{*}{ Variables } & \multicolumn{7}{|c|}{ Staphylococcus } \\
\hline & \multicolumn{2}{|c|}{ At 3 weeks } & \multicolumn{2}{|c|}{ At 6 weeks } & \multicolumn{2}{|c|}{ At 9 weeks } & \multirow{2}{*}{ p-value } \\
\hline & Mean & SD & Mean & SD & Mean & SD & \\
\hline Ball and Socket & 3.03 & 0.38 & 3.22 & 0.32 & 3.52 & 0.52 & $0.230(\mathrm{~ns})$ \\
\hline Locator & 3.23 & 0.36 & 3.57 & 0.68 & 3.87 & 0.64 & $0.183(\mathrm{~ns})$ \\
\hline p-value & \multicolumn{2}{|c|}{0.481 (ns) } & \multicolumn{2}{|c|}{$0.374(\mathrm{~ns})$} & \multicolumn{2}{|c|}{$0.472(\mathrm{~ns})$} & \\
\hline
\end{tabular}

*Significant $\mathrm{P}<0.05$, ns; non-significant $\mathrm{P}>0.05$

TABLE (4): Results of Two-way ANOVA for the effect of different variables on Staphylococcus count.

\begin{tabular}{|c|c|c|c|c|c|}
\hline Source & $\begin{array}{c}\text { Type III Sum of } \\
\text { Squares }\end{array}$ & df & Mean Square & $\mathrm{F}$ & Sig. \\
\hline Corrected Model & $2.309^{\mathrm{a}}$ & 5 & .462 & 1.822 & .146 \\
\hline Intercept & 348.298 & 1 & 348.298 & 1374.805 & .000 \\
\hline Attachment type & .687 & 1 & .687 & 2.712 & .113 \\
\hline Time period & 1.586 & 2 & .793 & 3.131 & .062 \\
\hline Attachment type $*$ Time period & .035 & 2 & .018 & .069 & .933 \\
\hline Error & 6.080 & 24 & .253 & & \\
\hline Total & 356.686 & 30 & & & \\
\hline Corrected Total & 8.389 & 29 & & & \\
\hline
\end{tabular}




\section{DISCUSSION}

The aim of this randomized crossover trial was to evaluate the microbial flora namely initial colonizer Strpetococcus and Staphylococcus spp. in peri-implant sulcular fluid samples of edentulous patients rehabilitated with ball and locator-retained implant overdentures. No significant difference was found in bacterial count between either of the two attachment systems at any of the evaluated time intervals.

Peri-implant bacterial biofilm is one of the important factors that influence the long-term prognosis of osseointegration. The formation of oral biofilm is initiated by the generation of an acquired pellicle and subsequent adherence of early colonizing species (spp). This initial species create the optimal environment for the accumulation of gram-negative anaerobic late colonizing microorganisms. ${ }^{17}$ The microbial diversity of oral biofilms in the periimplant sulcuar fluid depends on individual host factors such as oral hygiene, salivary composition and nutrition of each subject. ${ }^{18,19}$ On the other hand, important implant related factors include implant/ abutment materials and surface roughness as well as plaque-retentive sites of implant attachments or implant supra-structures..$^{20}$

All subjects maintained oral hygiene measures and microbiological swaps were collected at 3,6, and 9 weeks to detect any changes in the count of the initial colonizers between the two attachment systems. Previous studies reported that at a period of 3-5 months of undisturbed plaque formation, the microbiota in peri-implant mucosa was similar as around the teeth but extended further apically. ${ }^{21,22}$

Locator attachments are commonly used for mandibular implant overdenture retention because of the ease of replacement of components as well as the unique attachment design resulting from the low profile and dual alignment and retentive features of such systems. ${ }^{23}$ Nevertheless it can be speculated that the inner and outer retentive areas imparting those unique qualities to locator abutments may enhance the abutment colonization with early colonizing spp. However, based on the findings of the current study and the lack of significant difference in the bacterial count between the locator and ball attachment systems, the later assumption can be refuted. This finding can be attributed to the ease of cleaning which is permitted by both attachment systems. Further, It is acknowledged that strict oral hygiene measures and follow-up protocol that was followed might have influenced the results. Whereas in a dwelling with old frail patients and in a non-trial setting different outcomes could have been observed. Furthermore, the surface roughness of implant and abutment surfaces may play more of a role than the abutment design in the process of initial bacterial colonization and supragingival plaque formation. Several studies reported faster supra-gingival plaque formation on abutment surface with increased surface roughness compared to those with smoother surfaces. ${ }^{24-26}$ However, the different rate of bacterial colonization and plaque formation between smooth and rough surface was less obvious when oral hygiene measures were optimal. ${ }^{14}$

The Presence of streptococcus spp. in periimplant sulcus in this study corroborate with findings of other studies ${ }^{27,28}$ where high proportions of coccoid cells, a low number of Gram anaerobic species and periodontopathogens were isolated from healthy peri-implant pockets.

Further research, should focus on recruiting subjects with ball or locator retained overdentures who suffer from perimucositis or peri-implantitis and further assessment of oral microbiota in the periimplant sulcus to provide broader understanding of the whole biological picture and its potential influence on long-term clinical outcome. The influence of surface roughness on the microbial film formation in peri-implant sulcular fluid should also be evaluated. 


\section{CONCLUSIONS}

Within the limitations of this study, it can be concluded that there is no difference between the two attachment systems with regards to microbiological environment in the peri-implant/abutment sulcular fluid. It can also be suggested that the locator attachments are valid treatment alternative for ball abutments to retain mandibular 2-implant overdentures from a microbiological point of view.

\section{REFERENCES}

1. Doundoulakis JH, Eckert SE, Lindquist CC, et al. The implant-supported overdenture as an alternative to the complete mandibular denture. J Am Dent Assoc 2003; 134:1455-1458.

2. Davis DM. Implant-stabilized overdentures. Dent Update 1997; 24:106-109.

3. Kim HY, Lee JY, Shin SW, Bryant SR. Attachment systems for mandibular implant overdentures: A systematic review. J Adv Prosthodont 2012; 4:197-203.

4. Mensor MJ Jr. Attachment fixation for overdentures. Part I. J Prosthet Dent. 1977; 37:366-372.

5. Alsabeeha N, Payne A, Swain MV. Attachment systems for mandibular two implant overdentures: A review of the invitro investigations on retention and wear features. Int $\mathbf{J}$ Prosthodont 2009; 22:429-440.

6. Watson G, Payne AGT, Purton DG, Thomson WM. Mandibular implant overdentures: Comparative evaluation of prosthodontic maintenance during the first year of service using 3 different systems. Int J Prosthodont 2002; 15: 259-266.

7. Cune M, Burgers M, van Kampen F, de Putter C, van der Bilt A. Mandibular overdentures retained by two implants: 10-year results from a crossover clinical trial comparing ball-socket and bar-clip attachments. Int $\mathrm{J}$ Prosthodont 2010; 23: 310-317.

8. Chang HS, Hsieh YD, Hsu ML. Long-term survival rate of implant-supported overdentures with various attachment systems: A 20-year retrospective study. J Dent Sci 2015; 10: $55-60$.

9. Trakas H, Michalakis K, Kang K, Hirayama H. Attachment systems for implant retained overdentures: A literature review. Implant Dent 2006; 15:24-34.
10. Lachmann S, Kimmerle-Müller E, Gering K, Axmann D, Gomez-Roman G, Watzek G, Weber H. A comparison of implant supported bar-or ball retained mandibular overdentures: A retrospective clinical, microbiologic, and immunologic study of 10 edentulous patients attending a recall visit. Int J Prosthodont 2007; 20: 37-42.

11. Monroy T.B, Maldonado V. M, Martínez F.F, Barrios B.A, Quindós G, Vargas L-O S. Candida albicans, Staphylococcus aureus and Streptococcus mutans colonization in patients wearing dental prosthesis. Med Oral Patol Oral Cir Bucal 2005; 10:E27-E39

12. Smedberg JI, Svensäter G, Edwardsson S. The microflora adjacent to osseintegrated implants supporting maxillary removable prostheses. Clin Oral Implants Res 1993; 4: 165-171.

13. Esposito M, Hirsch J, Lekholm U, Thomsen P. Differential diagnosis and treatment strategies for biologic complications and failing oral implants. A review of the literature. Int J Oral Maxillofac Implants 1999; 14: 473-490.

14. Quirynen M, De Soete M, van Steenberghe D. Infectious risks for oral implants: a review of the literature. Clin Oral Implants Res 2002; 13: 1-19

15. Schweyen R, Arnold C, Setz JM, Hey J. Retentive characteristics of individual and prefabricated polyvinylsiloxane overdenture attachments: alternative treatment options for geriatric patients. Clin Oral Invest. 2018; https://doi. org/10.1007/s00784-018-2568-x.

16. Zarb, G., Bolender, C., Eckert, S., Jacob, R., Fenton, A. \& Mericske-Stern, R. (2003) Prosthodontic Treatment for Edentulous Patients, 12th edition, 211-425. St Louis: Mosby.

17. Whittaker CJ, Klier CM, Kolenbrander PE. Mechanisms of adhesion by oral bacteria. Annu Rev Microbiol 1996; 50: 513-552.

18. Niimi A, Ueda M. Crevicular Fluid in the Osseointegrated Implant Sulcus: A Pilot Study. Int J Oral Maxillofac Implants 1995; 10: 434-436

19. Heuer W, Kettenring A, Demling A, Stumpp SN, Gellermann E, Winkel A, Stiesch M. Microbial Diversity of PeriImplant Biofilms on Implant Fixed Bar and Telescopic Double Crown Attachments, J Oral Implantol 2013; 39: 648-654.

20. Heitz-Mayfield LJ, Lang NP. Comparative biology of chronic and aggressive periodontitis vs. peri-implantitis. Periodontol 2000. 2010; 53:167-181. 
21. Ericsson I, Berglundh T, Marinello C, Liljenberg B, Lindhe J. Long-standing plaque and gingivitis at implants and teeth in the dog. Clinical Oral Implants Research 1992; 3: 99-103.

22. Abrahamsson I, Berglundh T, Lindhe J. Soft tissue response to plaque formation at different implant systems. A comparative study in the dog. Clinical Oral Implants Research 1998; 9: 73-79.

23. Krennmair G, Semann R, Fazekas A, Ewers R. Patient preference and satisfaction with implant-supported mandibular overdentures retained with ball or locator attachments: A crossover clinical trial. Int J Oral Maxillofac Implants 2012; 27: 1560- 1568.

24. Quirynen M., Van der Mei HC, Bollen CML, Schotte, A., Marechal, M., Doornbusch, G.I., Naert, I., Busscher, H.J. $\&$ van Steenberghe, D. An in vivo study of the influence of surface roughness of implants on the microbiology of supra- and sub-gingival plaque. J Dent Res 1993; 72: 1304-1309.
25. Quirynen M, Bollen CML, Papaioannou W. Van Eldere J, van Steenberghe D. The influence of titanium abutments surface roughness on plaque accumulation and gingivitis. Short-term observations. Int J Oral Maxillofac Implants 1996; 11: 169-178.

26. Bollen CML, Papaioannou W, Van Eldere J, Schepers E, Quirynen M, van Steenberghe D. The influence of abutment surface roughness on plaque accumulation and peri-implant mucositis. Clinic Oral Implants Res 1996; 7: 201-211.

27. Mombelli, A., Buser, D. \& Lang, N.P. Colonization of osseointegrated titanium implants in edentulous patients. Early results. Oral Microbio Immunolog 1998; 3: 113-120.

28. Mombelli A, van Oosten MA, Schürch E Jr, Lang NP. The microbiota associated with successful or failing osseointegrated titanium implants. Oral Microbiol Immunol 1987; 2:145-151. 30. 